\title{
ELASTIC MODULUS MEASUREMENTS OF HUMAN LIVER AND CORRELATION WITH PATHOLOGY
}

\author{
Wen-Chun Yeh, ${ }^{\dagger}$ Pai-Chi Li, ${ }^{\dagger}$ Yung-Ming Jeng, ${ }^{\ddagger}$ Hey-Chi Hsu, ${ }^{\ddagger}$ Po-Ling Kuo,${ }^{\S}$ \\ Meng-Lin Li, ${ }^{\dagger}$ PeI-Ming Yang ${ }^{l l}$ and Po Huang LeE ${ }^{\mathrm{I}}$ \\ Departments of ${ }^{\dagger}$ Electrical Engineering, National Taiwan University, Taipei, Taiwan; ${ }^{\star}$ Pathology, ${ }^{\S}$ Physical \\ Medicine and Rehabilitation, National Taiwan University Hospital, Taipei, Taiwan; Department of "Internal \\ Medicine and ${ }^{\text {II }}$ Surgery, National Taiwan University Hospital, Taipei, Taiwan
}

(Received 26 September 2001; in final form 31 January 2002)

\begin{abstract}
Viral hepatitis causes fibrosis in the liver and may change mechanical properties of the liver. To evaluate the impact of fibrosis on elastic properties of human liver and to investigate potential benefits of ultrasonic elasticity imaging, 19 fresh human liver samples and 1 hepatic tumor (focal nodular hyperplasia) sample obtained during operations were studied. Simple 1-D estimates based on the cyclic compressionrelaxation method were performed. Elastic modulus values were derived from the predetermined strain (controlled by a step motor system) and the stress values (measured by an electronic balance). Each specimen subsequently received histologic examination and a grade of liver fibrosis was scored from 0 to 5 . Results show that the elastic modulus values were on the order of several hundreds to thousands of Pascals. The elastic modulus generally increased with the fibrosis grade, although some discrepancies existed at the middle grades of fibrosis (scores 1 to 3). The correlation between the fibrosis score and the elastic modulus was significant $(p<$ 0.01) based on the statistical analysis using the Pearson correlation method. In addition, the relation between the elastic modulus and the fibrosis grade generally exhibited a quadratic trend. It was concluded that severity of fibrosis had a good correlation with stiffness of the liver. Results also indicated that the elasticity imaging of the liver may provide significant clinical values if the elastic modulus can be accurately measured. (E-mail: paichi@cc.ee.ntu.edu.tw) (c) 2002 World Federation for Ultrasound in Medicine \& Biology.
\end{abstract}

Key Words: Elasticity, Elastic modulus, Liver elastic properties, Liver pathology, Fibrosis.

\section{INTRODUCTION}

Viral hepatitis, such as hepatitis B or C, may cause chronic inflammation of the liver and induce fibrosis in hepatic tissue. Fibrous bands between the acini of liver are similar to the internal skeletons of the soft parenchyma and can alter the elastic properties of liver tissue. The degree of fibrosis may range from fibrous expansion in the portal area to cirrhosis (Knodell et al. 1981). Cirrhosis may cause portal hypertension and induce complications such as intractable ascites and esophageal varix bleeding. In addition, the incidence rate of hepatocellular carcinoma is also higher in these patients. Thus, detecting cirrhosis and screening for malignancy in patients with chronic hepatitis are clinically important. Physicians typically screen these patients by using con-

Address correspondence to: Pai-Chi Li, Department of Electrical Engineering, National Taiwan University, No.1, Sec. 4, Roosevelt Road, Taipei, Taiwan 106. E-mail: paichi@cc.ee.ntu.edu.tw ventional B-mode ultrasound (US). Cirrhosis appears as patterns with coarse texture and nodular surface. However, detection of early stage cirrhosis using B-mode US is limited (Yang et al. 1988). On the other hand, cirrhotic livers have abundant fibrosis septum between the acini and have been known to be harder than the healthy liver by palpation. Because ultrasonic elasticity imaging can visualize the tissue stiffness and can provide physicians with a "virtual finger" to probe the elasticity inside of the body (Céspedes et al. 1993; Emelianov et al. 1995; Ophir et al. 1997; Sarvazyan et al. 1998), it may be beneficial in cirrhosis detection.

Ultrasonic elasticity imaging has been extensively studied during the past several years. Among the research works, O'Donnell et al. (1994) and Skovoroda et al. $(1994,1995)$ indicated that quantitative elasticity imaging consists of three main components: speckle tracking and evaluation of tissue deformation, estimation of strain tensor and reconstruction of the elastic modulus. In other words, elasticity imaging directly displays the tis- 
sue stiffness. If the elastic modulus of healthy liver, cirrhotic liver and hepatic tumors can be accurately measured, elasticity imaging has the potential to differentiate liver lesions of different natures. Accurate estimation of the elastic modulus of tissue is a necessary step to turn elasticity imaging into an effective clinical tool (Chen et al. 1996; Erkamp et al. 1998; Krouskop et al. 1998).

Several research groups have studied the elastic properties of liver. Wang et al. (1992) combined an optical method with an indentation technique to investigate the biomechanical response of pig hepatic tissue. Results showed that the liver was obviously a viscoelastic material. Liu and Bilston (2000) investigated the viscoelastic characteristics of the liver tissue and the Maxwell model was employed to describe its mechanical behavior. Yamashita and Kubota $(1994,1995)$ estimated the elastic properties of human liver by measuring the internal displacement and strain. Emelianov et al. (1998) studied the elastic properties of hepatic hemangiomas and found that hemangiomas were harder than the background liver tissue. Chen et al. (1996) studied the Young's modulus of bovine liver and muscle and compared them with the results from direct mechanical measurements. Despite the numerous research results, quantitative and direct measurements of elastic properties of fresh human liver tissues are still lacking. It was the primary purpose of this study to measure the elastic modulus of fresh human liver samples from patients with various liver diseases. Results are also correlated with pathology.

The paper is organized as follows. The following section describes preparation of liver samples, the experimental setup and the method for elastic modulus measurements. Then, the measurement results of liver elastic modulus at different fibrosis grades are summarized. Finally, the correlation between the elastic modulus and the fibrosis grade is investigated with a discussion on potential experimental errors and the strain hardening effect.

\section{MATERIALS AND METHODS}

A total of 19 fresh human liver samples and 1 hepatic tumor (focal nodular hyperplasia) were included in this study. The liver samples were obtained from patients with liver disease during operations at National Taiwan University Hospital (NTUH). There were 18 adult patients (mean age was 55 years old) and 1 child patient (10 months old). The gender ratio of male to female was 16 to 3 . The underlying diseases of these patients were hepatocellular carcinoma in 14 patients, focal nodular hyperplasia in 2 patients, terminal liver disease in 2 patients and liver abscess in 1 patient.

For each patient, a triangular or cubic sample was

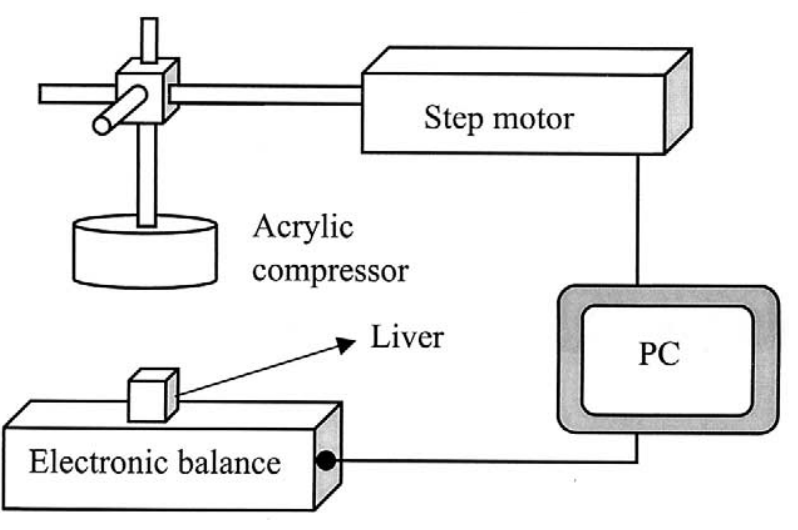

Fig. 1. Block diagram of the measurement setup.

obtained from the surgical specimen immediately after it was sent to the Department of Pathology at NTUH. Each sample was preserved in a small plastic bag filled with normal saline solution at $4^{\circ} \mathrm{C}$. The bag was then packed in ice and transported to the Ultrasonic Imaging Laboratory at the Department of Electrical Engineering, National Taiwan University. Measurements were made within $48 \mathrm{~h}$ after the operation.

In the Ultrasonic Imaging Laboratory, the specimens were cut to $1 \mathrm{~cm}^{3}$ cubes by using a surgical blade. After cutting, all prepared samples were preserved in a normal saline solution for at least $1 \mathrm{~min}$ before measurements were performed to prevent dehydration. The venous vascular structure was avoided during cutting. These small cubic specimens were used for direct elastic modulus measurements. The weight for each cubic specimen was around $1.1 \mathrm{~g}$ measured by an electronic balance (OHAUS 1P12KS, Florham Park, NJ) and the height of each specimen was measured by a ruler with a minimum scale of $1 \mathrm{~mm}$. For the cirrhotic liver, the samples were cut $10 \mathrm{~mm}$ in height. For normal (or close-to-normal) liver, the samples were generally softer and they were cut approximately $11 \mathrm{~mm}$ in height to compensate for the mass-density-based deformation.

The electronic balance had a readability of $0.1 \mathrm{~g}$ and was placed under the specimen to measure the applied load. Figure 1 shows that the experimental setup consisted of the electronic balance, an acrylic plate as the compressor positioned by a step motor system (Q-Sync, Hsin-Chu, Taiwan) and a personal computer for central control and data acquisition.

Simple 1-D estimates based on the cyclic compression-relaxation method was used (Kuo et al. 2001). Values of the elastic modulus were derived from the predetermined strain (controlled by the step motor system) and the stress (measured by the electronic balance) (Aklonis 1983). After putting each sample on the center of the electronic balance, the acrylic compressor was 
carefully positioned toward the liver sample. For each sample, the compression procedures described below were used to determine the elastic modulus. The procedures were based on the incremental laws (Fung 1993). First, the initial strain state was defined at the initial contact between the liver sample and the acrylic compressor. The initial contact was indicated when reading of the electronic balance started to increase. Second, the acrylic compressor was advanced by $500 \mu \mathrm{m}, 1000 \mu \mathrm{m}$ or $1500 \mu \mathrm{m}$ (set by the computer) and they corresponded to $5 \%, 10 \%$ or $15 \%$ preload strains (the height of the liver sample was $10 \mathrm{~mm}$ ). At each preload strain, the sample was then cyclically compressed at an average compression rate of $7.1 \mathrm{~mm} / \mathrm{min}(1.2$ steps $/ \mathrm{s}$ rate with $100 \mu \mathrm{m} / \mathrm{step}$ ) with a maximum compression of $500 \mu \mathrm{m}$. Note that the additional strain during cyclic compression was assumed to be infinitesimal. Each measurement consisted of two consecutive compression-relaxation cycles and three measurements were made under each stain condition. Stiffness of the machine was also investigated. The estimated elastic modulus of the measurement system was $5.3 \times 10^{7}$ Pascals and it was far larger than that of the liver samples. Thus, deformation of the measurement system can be ignored.

Consecutive readings of the electronic balance were acquired from the digital output of the balance at a rate of $5 \mathrm{~Hz}$. The readings were stored into a personal computer via an RS232 port. The area of tissue surface between the sample and the electronic balance was 1 $\mathrm{cm}^{2}$. The elastic modulus for each specimen was computed from the slope of the stress-strain curve, where the strain was defined as the ratio of total deformation to the initial height. Because the compressor was positioned by the computer-controlled step-motor, strain at each position was readily obtained. For every compression, the maximum of consecutive readings from the electronic balance was obtained and divided by the area of contacting surface (i.e., $1 \mathrm{~cm}^{2}$ ) to determine the corresponding stress. Figure 2a shows typical readings from the electronic balance as a function of time in a measurement under $10 \%$ preload strain. The horizontal axis is time and the vertical axis is reading of the electronic balance. Each circle during the second cycle represents the maximum point for each compression step. The first compressionrelaxation cycle was used for preconditioning and the data were not used for elastic modulus estimation (Fung 1993). Figure $2 b$ plots the selected maxima shown in Fig. $2 \mathrm{a}$ with the horizontal axis and vertical axis being converted to corresponding strain and stress, respectively. The solid line represents the best-fit line and the elastic modulus is determined by the slope of the best-fit line. The average value from 3 measurements was calculated for each strain condition.

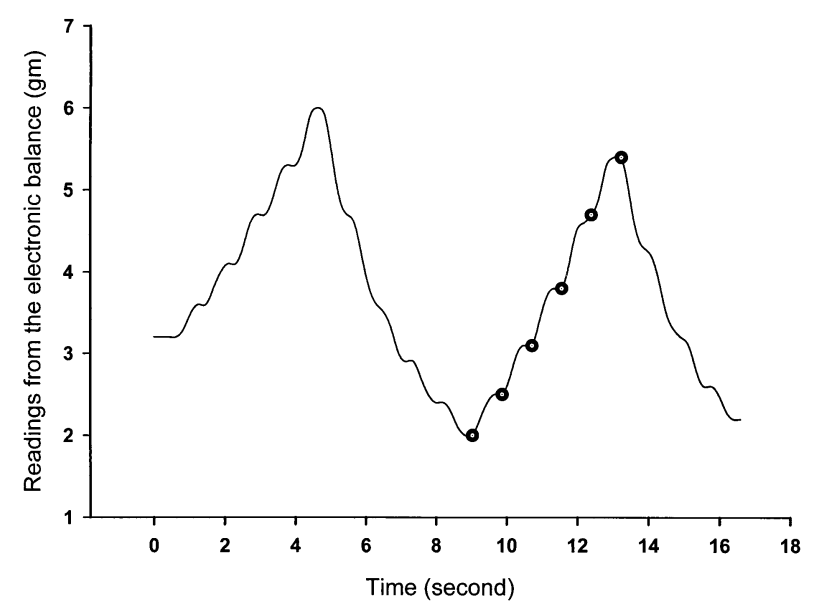

(a)

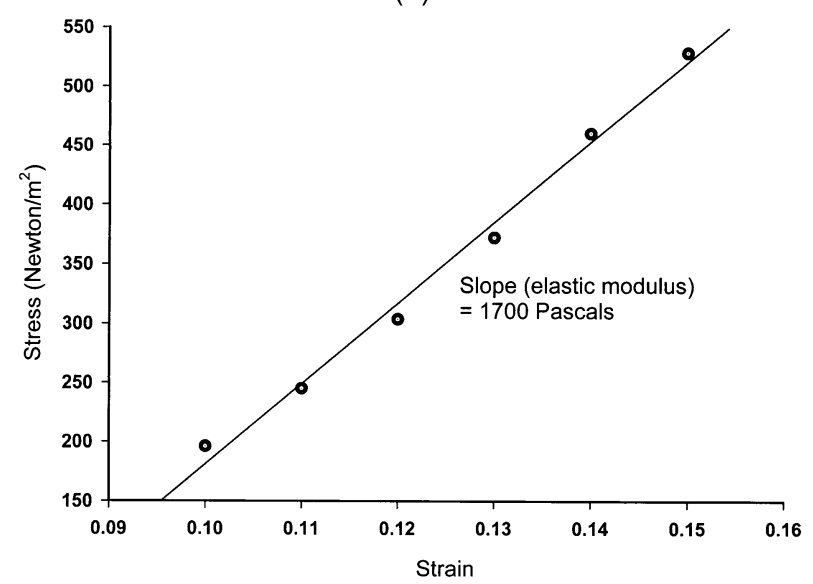

(b)

Fig. 2. Readings from the electronic balance as a function of time under a preload $10 \%$ strain. (a) Solid line = the measurement curve; each circle $=$ the maximum point at each step during compression in the second cycle. (b) Stress vs. strain. (-) the best-fit line; the slope is defined as the elastic modulus.

After the elastic modulus measurements were done, the specimens were subsequently fixed in formalin and embedded in paraffin; 5- $\mu \mathrm{m}$ sections were cut and stained with hematoxylin and erosin for histologic examinations. Fibrosis scores were assigned according to the criteria of the METAVIR Cooperative Study Group (Poynard et al. 1997). Liver fibrosis was scored from 0 to 4 according to the following definition: $0=$ no fibrosis; $1=$ portal fibrosis without septa; $2=$ septa fibrosis; $3=$ numerous septa without cirrhosis and $4=$ cirrhosis. In cirrhotic livers, the widths of fibrotic bands varied and the score was further divided so that a score of 4 represented thin fibrotic bands and a score of 5 was for thick fibrotic bands. The fatty change of the liver tissue was also evaluated. It was scored from 0 to 3 , defined as the following: $0=$ no fatty change; $1=$ mild fatty change; 
Table 1. Average elastic modulus with SD

\begin{tabular}{|c|c|c|c|c|}
\hline \multirow{2}{*}{$\begin{array}{l}\text { Fibrosis } \\
\text { score }\end{array}$} & \multirow{2}{*}{$\begin{array}{c}\text { No. of } \\
\text { specimen }\end{array}$} & \multicolumn{3}{|c|}{ Elastic modulus under preload strain $(\mathrm{p})$} \\
\hline & & $5 \%$ & $10 \%$ & $15 \%$ \\
\hline 0 & 3 & $640 \pm 80$ & $1080 \pm 160$ & $2000 \pm 630$ \\
\hline 1 & 1 & 1260 & 2770 & 6800 \\
\hline 2 & 2 & $1050 \pm 240$ & $1790 \pm 670$ & $5400 \pm 3470$ \\
\hline 3 & 3 & $870 \pm 170$ & $1820 \pm 290$ & $5390 \pm 2780$ \\
\hline 4 & 7 & $1110 \pm 170$ & $2370 \pm 360$ & $6270 \pm 1020$ \\
\hline 5 & 3 & $1650 \pm 110$ & $4930 \pm 930$ & $19980 \pm 6950$ \\
\hline
\end{tabular}

$2=$ moderate fatty change and $3=$ marked fatty change. The measured elastic modulus values were also correlated with the pathologic findings using the Pearson correlation method (Norusis 1993).

\section{RESULTS}

The mean values and SD of the elastic modulus and the numbers of the test samples in different fibrosis scores were listed in Table 1. The mean elastic modulus generally increased with the increased fibrosis score except for scores 1 and 2, where the number of samples was 1 and 2, respectively. The elastic modulus of severe fibrotic liver tissue (i.e., score 4 and 5) was much larger than that of healthy tissue. Figure $3 \mathrm{a}, \mathrm{b}$ and $\mathrm{c}$ shows distribution of the elastic modulus for different fibrosis scores under the preload strain conditions at 5\%, 10\% and $15 \%$, respectively. The horizontal axis is the fibrosis score and the vertical axis is the elastic modulus. The solid lines are best-fit curves based on the nonlinear (quadratic) regression method.

Figure 4 shows the elastic modulus as a function of strain for the samples with fibrosis scores 0,4 and 5 . The horizontal axis is the strain and the vertical axis is the elastic modulus on a logarithmic scale. It is shown that the elastic modulus increased approximately exponentially with the preload strain. The vertical dashed lines represent the actual ranges of the preload strains after considering potential measurement errors. It will be further discussed in the following section.

The Pearson correlation method was also used to evaluate the correlation between the fibrosis score and the value of the elastic modulus. The Pearson correlation coefficients ( $r$ ) are listed in Table 2 . The $r$ values between the fibrosis score and the value of elastic modulus under $5 \%, 10 \%$ and $15 \%$ preload strain conditions were 0.702 , 0.669 and 0.626 , respectively. These values indicated that positive correlation existed and the correlation was significant at the 0.01 level $(p<0.01)$. The correlation values between the elastic modulus measured at different preload strains were all higher than 0.850 . The correlation values between the fatty change score and the elastic

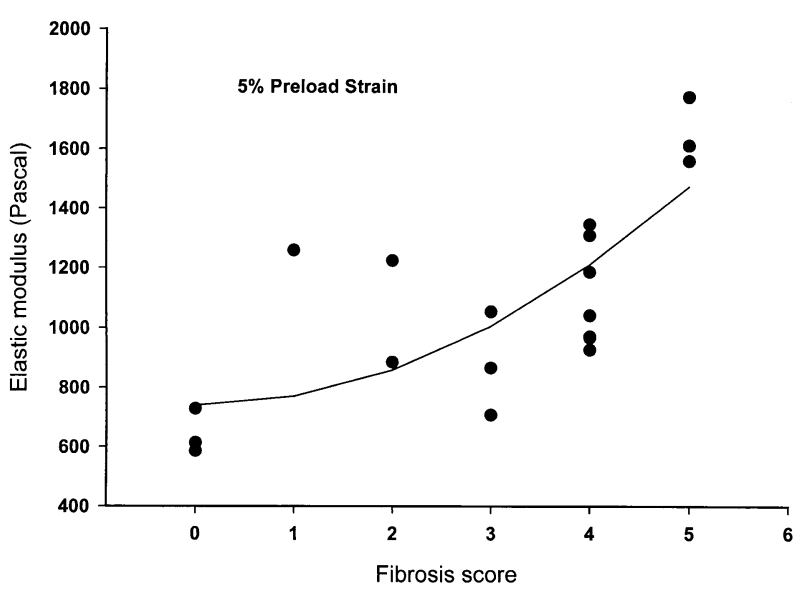

(a)

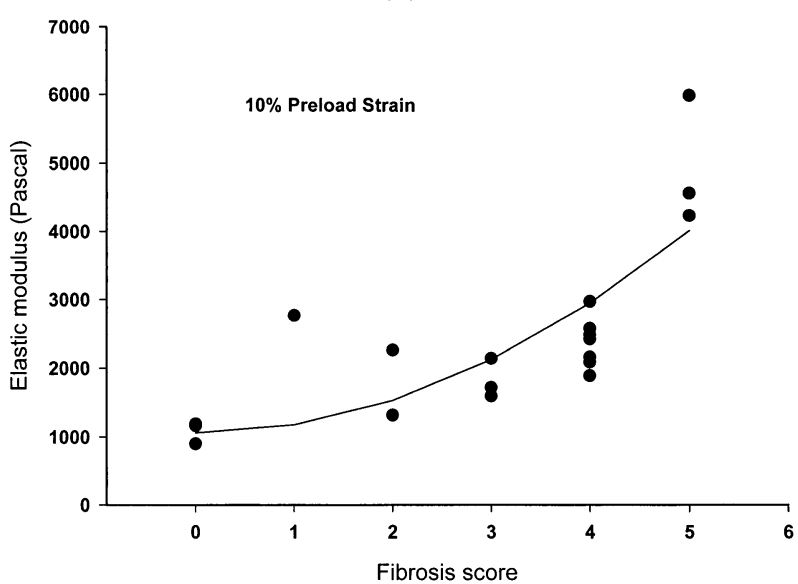

(b)

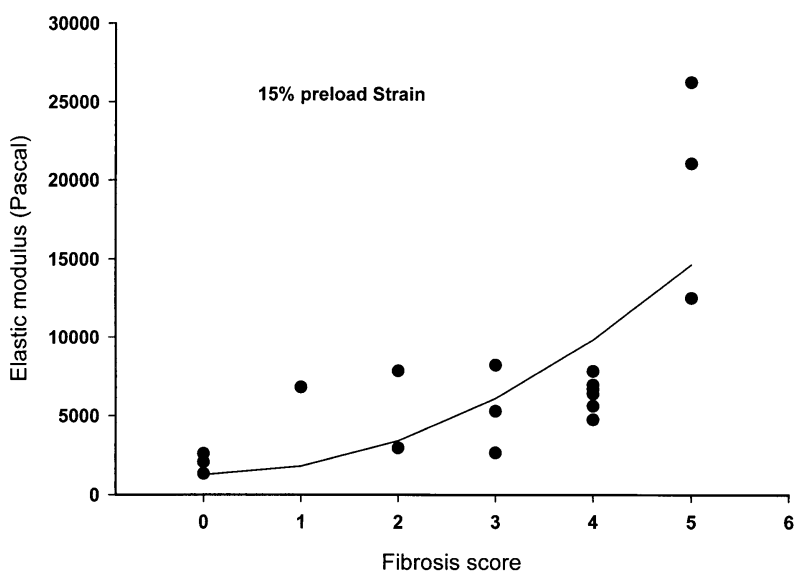

(c)

Fig. 3. Elastic modulus vs. fibrosis score. (-) the regression curve under (a) $5 \%$ preload strain, (b) $10 \%$ preload strain, and (c) $15 \%$ preload strain. The regression curves are nonlinear and have a quadratic trend.

modulus are also listed in the same table. There was no obvious correlation between the fatty change score and the elastic modulus. 


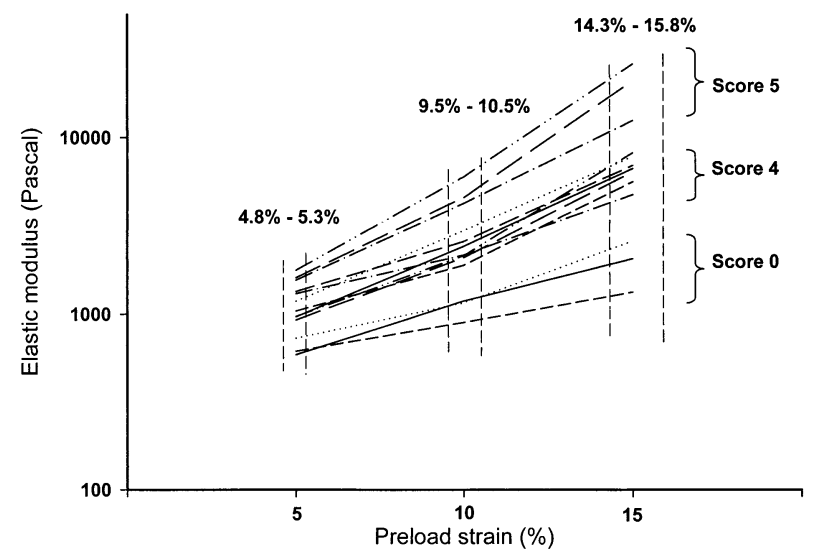

Fig. 4. Elastic modulus on a logarithmic scale vs. strain. Only data for fibrosis scores of 0,4 and 5 are shown. The vertical dash lines represent the ranges of $5 \%, 10 \%$ and $15 \%$ preload strains after considering potential measurement errors.

\section{DISCUSSION AND CONCLUSIONS}

This study investigated the relationship between the fibrosis grade and the elastic modulus. The elastic modulus was directly measured. Results show that severity of fibrosis has a good correlation with the elastic modulus. The elastic modulus of fresh human liver at $5 \%$ preload strain ranged from 590 to 1730 Pascals at different fibrosis stages. The results are similar to the measurements of bovine liver under $1 \%$ to $5 \%$ strain (Chen et al. 1996). The mean values of elastic modulus in Table 1 generally increased with increasing fibrosis grades except for scores 1 and 2. In other words, the cirrhotic tissue (scores 4 and 5) is harder than the healthy tissue (score 0). Yamashita and Kubota $(1994,1995)$ estimated elasticity of soft tissue by the measurement of internal displacement and strain. It was also found that the healthy liver tissue had a relatively larger local displacement than the cirrhotic liver (i.e., the cirrhotic liver was stiffer than the healthy liver). Such a finding is also consistent with the results shown in this paper.

The regression curves between the fibrosis score and the elastic modulus generally had a quadratic trend, as shown in Fig. 3. Discrepancies existed in some samples with fibrosis scores of 1 to 2 at all strain conditions and in some samples with a score of 3 under a high strain condition. This may be due to the small number of samples for fibrosis scores of 1 and 2, measurement errors, and other changes in the liver tissue that may affect liver stiffness. For example, the fatty change of liver fills some of the liver cells with triglyceride and may alter the mechanical properties of liver. In our study, the noncirrhotic liver samples with fatty change seemed harder than the tissue with less fatty change at the same fibrosis score (e.g., fibrosis scores 2 and 3). However, no statistical significance was found, as shown in Table 2. The biologic tissue is a composite material and it is difficult to separate the influence of each component of the tissue on the total in modulus estimates.

Fresh liver samples were used in this study without formalin fixation. This is to avoid the increased stiffness caused by formalin fixation as found in the literature (Hoffmeister et al. 1994). However, there were some difficulties in cutting the fresh liver samples. The cut surface of liver was difficult to make very smooth especially for soft healthy liver samples. To reduce the measurement errors caused by uneven surface and to ensure good contact between the liver sample and the compressor, the starting preload strain was $5 \%$ instead of the $0 \%$ strain used by Kuo et al. (2001) for tendon stiffness measurements. Nevertheless, errors may exist in measuring the height of the specimen. The height of the specimen was cut to be $10 \mathrm{~mm}$ measured by a ruler with a minimum scale of $1 \mathrm{~mm}$. Thus, the actual height may have ranged between $9.5 \mathrm{~mm}$ and $10.5 \mathrm{~mm}$. Taking the potential measurement errors into account, the actual preload strains ranged from $4.8 \%$ to $5.3 \%, 9.5 \%$ to $10.5 \%$ and $14.3 \%$ to $15.8 \%$ for the three prespecified preload strains at $5 \%, 10 \%$ and $15 \%$, respectively. Influence of the measurement error is shown in Fig. 4. The ranges of preload strains are shown as the vertical dashed lines after considering potential length measurement errors. Values of elastic modulus at the highest (15\%) preload strain vary the most due to the fact that the elastic modulus increased nonlinearly with the applied strain.

Table 2. The Pearson correlation between the fibrosis score /fatty change score and the elastic modulus

\begin{tabular}{lccccc}
\hline & & & & \\
& Fibrosis score & $\begin{array}{c}\text { Fatty } \\
\text { change score }\end{array}$ & EM (5\%PS) & EM (10\%PS) & EM (15\%PS) \\
\hline Fibrosis score & 1 & 0.162 & $0.702^{*}$ & $0.669^{*}$ & $0.626^{*}$ \\
Fatty change score & 0.162 & 1 & 0.344 & 0.251 & 0.270 \\
EM (5\% PS) & $0.702^{*}$ & 0.344 & 1 & $0.912^{*}$ & $0.856^{*}$ \\
EM (10\% PS) & $0.669^{*}$ & 0.251 & $0.912^{*}$ & 1 & $0.958^{*}$ \\
EM (15\% PS) & $0.626^{*}$ & 0.270 & $0.856^{*}$ & $0.958^{*}$ & 1 \\
\hline
\end{tabular}

* Correlation is significant at the 0.01 level; EM = elastic modulus; PS = preload strain. 
Table 3. Elastic modulus of normal liver, cirrhotic liver and hepatic tumors

\begin{tabular}{|c|c|c|c|c|c|c|c|}
\hline \multirow{3}{*}{$\begin{array}{c}\begin{array}{c}\text { Preload } \\
\text { strain }\end{array} \\
0\end{array}$} & \multicolumn{7}{|c|}{ Elastic modulus (pa) } \\
\hline & \multicolumn{3}{|c|}{ Liver parenchyma (mean value) } & \multicolumn{4}{|c|}{ Hepatic tumors } \\
\hline & Normal & $\begin{array}{l}\text { Cirrhosis (fibrosis } \\
\text { score: } 4 \text { ) }\end{array}$ & $\begin{array}{l}\text { Cirrhosis (fibrosis } \\
\text { score: } 5 \text { ) }\end{array}$ & $\begin{array}{l}\text { Hepatocellular } \\
\text { carcinoma }\end{array}$ & Cholangiocarcinoma & $\begin{array}{r}\text { Focal nodular } \\
\text { hyperplasia }\end{array}$ & Hemangioma* \\
\hline $5 \%$ & 640 & 1110 & 1650 & $\begin{array}{l}\text { Softer than healthy } \\
\text { liver }\end{array}$ & 3000 & 1080 & $\begin{array}{l}\text { Stiffer than healthy } \\
\text { liver }\end{array}$ \\
\hline $10 \%$ & 1080 & 2370 & 4930 & $\begin{array}{l}\text { Softer than healthy } \\
\text { liver }\end{array}$ & 12100 & 2520 & $\begin{array}{l}\text { Stiffer than healthy } \\
\text { liver }\end{array}$ \\
\hline
\end{tabular}

* Emelianov et al. 1998

Nevertheless, distinction between the healthy and the cirrhotic samples is still obvious. Figure 4 is also consistent with the results shown in Table 2 , in that the correlation increases as the preload strain decreases.

Several issues regarding accuracy and significance of the results need to be further discussed. The first issue is the harmonic components of the waveform of the load-time function. The waveform of the readings from the electronic balance (as shown in Fig. 2a) was triangular. Thus, the measurements may have been influenced by the harmonic components of such a waveform. Nonetheless, because the amplitude ratio of the largest harmonic component (third harmonic) to that of the fundamental component is only $11 \%$, effects of the harmonic components on the correlation relations shown in Table 2 are minimal. The second issue is that elastic properties of the samples may have changed with time after they were removed from the body. According to the experiment protocol, a piece of liver tissue was cut when the surgical specimen was obtained, and the tissue sample was conserved in normal saline at $4^{\circ} \mathrm{C}$. Then the samples (in normal saline) were stored in an icebox during transportation. All samples were measured within $48 \mathrm{~h}$ (most within $30 \mathrm{~h}$ ). Such a time period is the same as the study done by Chen et al. (1996). On the other hand, Krouskop et al. (1998) reported that the elasticity of breast and prostate tissues did not change within $2 \mathrm{~h}$ after the tissues were excised. However, there were no data available to discuss how the elastic properties of the liver tissue change with time after it is removed. Thus, the elastic modulus estimated in our experiments may be different from that of the living tissue.

In our experiments, data from the second compression cycle were used. Although there is evidence of loss in the peak load from the first to the second cycle, Fung (1993) showed that the curve of the second cycle was close to that of the third cycle, but different from that of the first cycle for tendon. Using the second cycle for elastic modulus estimation may produce small errors, but the increased stiffness caused by deformation and dehydration of the tissue can be avoided.
The viscoelastic properties of liver samples under cyclic compression were also studied. In our study, the phase shift between the applied strain and the load measured by the electronic balance was around $16^{\circ}$. (Given the phase delay, complex modulus, storage modulus and loss modulus were derived) (Tschoegl 1989). The loss modulus was noticeable for such a phase shift. Nonetheless, the value of the real component of the complex modulus was still close to that of the absolute modulus.

The compression rate used in this study was 0.12 Hz. As shown in Fig. 2a, the stress-relaxation phenomenon occurred following each compression step. Krouskop et al. (1998) estimated the elastic moduli of breast and prostate tissues under different compression rates. The estimated elastic moduli under $0.1 \mathrm{~Hz}$ of compression had no differences from those under 1.0 and $4.0 \mathrm{~Hz}$ of compression. Moreover, the slower compression rate used in this study is still appropriate for clinical applications of elasticity imaging if a similar rate is applied.

A hard tumor sample (cholangiocarcinoma) was found during our preliminary study. The elastic modulus was 3000 Pascals under 5\% preload strain and 12,100 Pascals under $10 \%$ preload strain. Another malignant tumor sample (hepatocellular carcinoma) was also available. However, the tissue was too soft to maintain the shape after cutting and the elastic modulus could not be measured by our system. The two special cases were consistent with the experience from pathologists. A benign tumor (focal nodular hyperplasia) was also received. It was stiffer than healthy liver and its elastic modulus was similar to that of cirrhosis with a score of 4 (1080 Pascals under 5\% preload strain, 2520 Pascals under $10 \%$ preload strain). The elastic properties of other benign tumors such as hemangioma were studied by Emelianov et al. (1998) based on ultrasonic elasticity imaging, instead of direct measurements used in our study. It was found that the human hepatic hemangiomas were harder than the background liver tissue. Results obtained from our study and the paper by Emelianov and colleagues are summarized in Table 3 . Table 3 provides a reference for liver elasticity imaging for the purpose of 


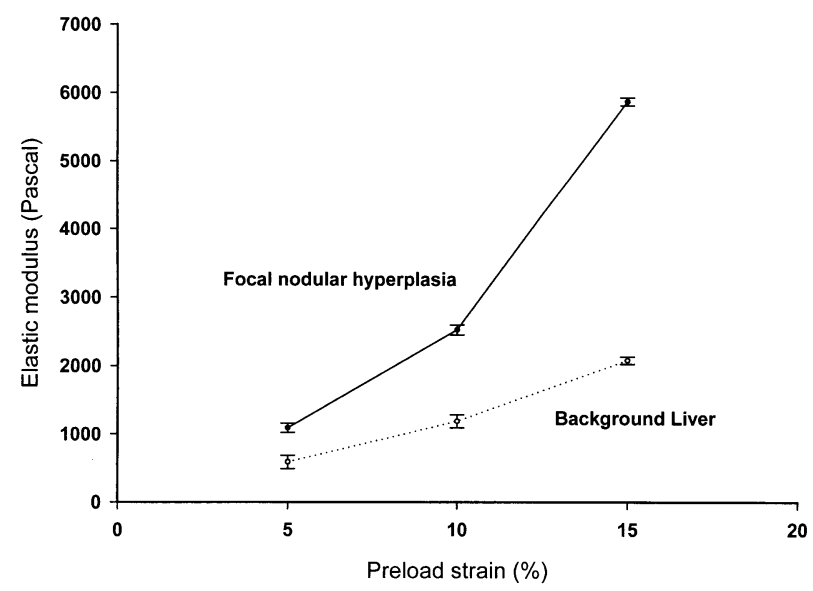

(a)

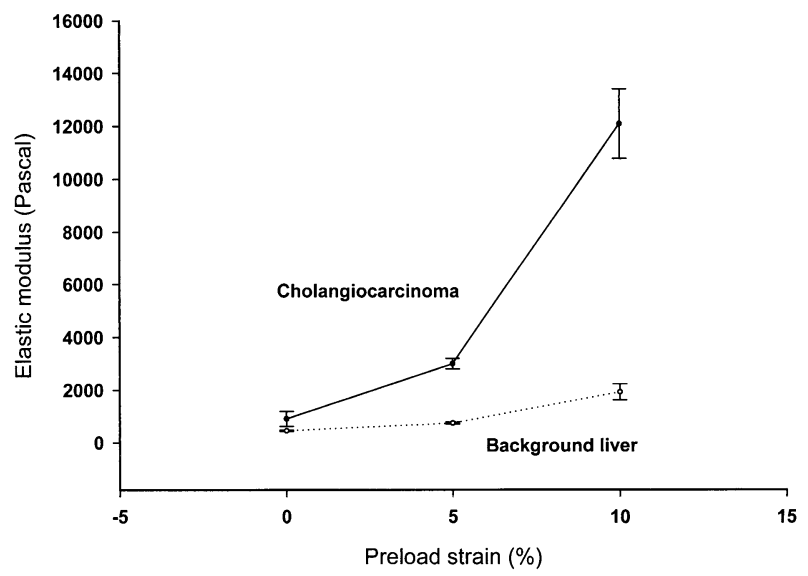

(b)

Fig. 5. Elastic modulus vs. strain. (-) the mean values for tumors; (----) the mean values for background liver, with error bars indicating \pm 1 SD. (a) Focal nodular hyperplasia vs. background liver; (b) cholangiocarcinoma vs. background liver.

identifying the cirrhotic liver and the nature of hepatic tumors.

Chen et al. (1996) found that the stress-strain curve becomes noticeably nonlinear when tissue strain exceeded $10 \%$. As the load further increases, the stressstrain curve becomes exponential. The nonlinearity is also known as the strain hardening effect. The strain hardening effect is demonstrated in Fig. 4, in that the elastic modulus increases faster at higher strains. Such a phenomenon is present for all specimens, including both liver tissues and tumors. Also note that the strain hardening effect is more apparent for stiffer tissues. Finally, Fig. 5a and b shows the elastic modulus as a function of strain for the tumors (focal nodular hyperplasia and cholangiocarcinoma, respectively) and the associated background liver tissues. The strain hardening effect between the two cases is also compared. The slope changes are larger for the tumor than for the background healthy liver tissue. The differences of the strain hardening effect among tissues may be utilized to enhance the contrast between tissues with different elastic properties (Erkamp et al. 2000).

Acknowledgements-The authors thank Dr. Pau-Chung Chen at College of Public Health of National Taiwan University for his great help in statistical analysis. The reviewers' comments are also greatly appreciated. This project was partially supported by the National Science Council of R.O.C. under Grant NSC 90 to 2213-E-002 to 127.

\section{REFERENCES}

Aklonis JJ. Introduction to polymer viscoelasticity. 2nd ed. New York: John Wiley \& Sons, 1983:7-9.

Céspedes I, Ophir J, Ponnekanti H, Maklad N. Elastography: Elasticity imaging using ultrasound with application to muscle and breast in vivo. Ultrason Imaging 1993;15:73-88.

Chen EJ, Norvokovski J, Jenkins WK, O’Brien WD Jr. Young's modulus measurements of soft tissues with application to elasticity imaging. IEEE Trans Ultrason Ferroelect Freq Control 1996;43(1): 191-194.

Emelianov SY, Lubinski MA, Weitzel WF, et al. Elasticity imaging for early detection of renal pathology. Ultrasound Med Biol 1995; 21(7):871-883.

Emelianov SY, Rubin JM, Lubinski MA, Skovoroda AR, O’Donnell M. Elastic imaging of liver: Is a hemangioma hard or soft. IEEE Ultrason Sympos 1998;2:1749-1752.

Erkamp RQ, Emelianov SY, Skovoroda AR, Chen X, O'Donnell M. Measuring the elastic modulus of small tissue sample. Ultrason Imag 1998;20(1):17-28.

Erkamp RQ, Wiggins P, Skovoroda AR, Emelianov SY, O'Donnell M. Exploiting strain-hardening of tissue to increase contrast in elasticity imaging. IEEE Ultrason Sympos 2000;2:1833-1836.

Fung YC. Biomechanics: Mechanical properties of living tissues. New York: Springer-Verlag, 1993:259-263.

Hoffmeister BK, Verdun ED, Wickline SA, Miller JG. Effect of collagen on the anisotropy of quasi-longitudinal mode ultrasonic velocity in fibrous soft tissues: A comparison of fixed tendon and fixed myocardium. J Acoustic Soc Am 1994;96(4):1957-1964.

Knodell RG, Isaac KG, Black WC, et al. Formation and application of a numerical scoring system for assessing histological activity in asymptomatic chronic active hepatitis. Hepatology 1981;1(5):431435.

Krouskop TA, Wheeler TM, Kallel F, Garra BS, Hall T. Elastic moduli of breast and prostate tissue under compression. Ultrason Imaging 1998;20:260-274.

Kuo PL, Li PC, Li ML. Elastic properties of tendon measured by two different approaches. Ultrasound Med Biol 2001;27(9):1275-1284.

Liu Z, Bilston L. On the viscoelastic character of liver tissue: Experiments and modeling of the linear behavior. Biorheology 2000; 37(3):191-201.

Norusis MJ. SPSS ${ }^{\circledR}$ for Windows ${ }^{\mathrm{TM}}$ : Base system user's guide, release 6.0. Chicago, IL: SPSS, Inc., 1993.

O'Donnell M, Skovoroda AR, Shapo BM, Emelianov ST. Internal displacement and strain imaging using ultrasonic speckle tracking. IEEE Trans Ultrason Ferroelec Freq Control 1994;41(3):314-325.

Ophir J, Kallel F, Varghese T, et al. Elastography: A systems approach. Int J Imaging Syst Technol 1997;8:89-103.

Poynard T, Bedossa P, Opolon P. Natural history of liver fibrosis progression in patients with chronic hepatitis C. The OBSVIRC, METAVIR, CLINIVIR, and DOSVIRC groups. Lancet 1997;349: $825-832$.

Sarvazyan AP, Rudenko OV, Swanson SD, Fowlkes JB, Emelianov SY. Shear wave elasticity imaging: A new ultrasonic technology of medical diagnostics. Ultrasound Med Biol 1998;24(9):1419-1435.

Skovoroda AR, Emelianov ST, Lubinski MA, et al. Theoretical analysis and verification of ultrasound displacement and strain imaging. IEEE Trans Ultrason Ferroelec Freq Control 1994;41(3):302-313. 
Skovoroda AR, Emelianov ST, O’Donnell M. Tissue elasticity reconstruction based on ultrasonic displacement and strain images. IEEE Trans Ultrason Ferroelec Freq Control 1995;42(4):747-765.

Tschoegl NW. The phenomenological theory of linear viscoelastic behavior: An introduction. New York: Springer-Verlag, 1989:5763.

Wang BC, Wang GR, Yan DH, Liu YP. An experimental study on biomechanical properties of hepatic tissue using a new measuring method. Biomed Mat Eng 1992;2(3):133-138.
Yamashita Y, Kubota M. Ultrasonic characterization of tissue hardness in the in vivo human liver. IEEE Ultrason Symp 1994;3:14491453.

Yamashita Y, Kubota M. Ultrasonic imaging of elasticity of soft tissue based on measurement of internal displacement and strain. IEEE Ultrason Symp 1995;2:1207-1211.

Yang PM, Huang GT, Lin JT, et al. Ultrasonography in the diagnosis of benign diffuse parenchymal liver disease: A prospective study. J Formosan Med Assoc 1988;187(10):966-977. 